\title{
Recurrent patterns of chromosome variation in a species group
}

\author{
A. S. Wilby and \\ J. S. Parker
}

School of Biological Sciences, Queen Mary College

(University of London), Mile End Road, London

E1 4NS, U.K.

The chromosome characteristics of five closely-related species in Rumex subgenus Acetosa are considered. All are dioecious diploids with $2 n=12+\mathrm{XX}$ in females and $2 n=12+\mathrm{XY} 1 \mathrm{Y} 2$ in males. The autosomes of all species are very similar, all highly acrocentric and displaying apparent homoeology, and only two chromosome changes have occurred in the evolution of the group - shift of an NOR and deletion of part of the long arm of chromosome 6 . The heterochromatic Y-chromosomes are more variable and only two species cannot be identified by examination of the Ys alone. Hypervariability in centromere location is characteristic of Ys in the whole subgenus although there is no quantitative variation in heterochromatin. On the autosomes, parallel polymorphisms for heterochromatic supernumerary segments on the short arms of pairs 1, 5 and 6 are found in 4 of the 5 species, and euchromatic B-chromosomes are common in three species. These recurrent patterns of chromosome variation emphasise the close relationships within the species group.

\section{INTRODUCTION}

Groups of closely-related organisms sometimes exhibit similar patterns of polymorphism. Thus the complex shell colour and banding polymorphisms in Cepaea nemoralis have counterparts in the sibling species $C$. hortensis, while the chromosome 3 inversion polymorphisms of Drosophila pseudoobscura are shared by $D$. persimilis (Dobzhansky, 1970). Two explanations can be advanced to explain these parallelisms. Firstly, the polymorphisms may be more ancient than the speciation event being present in the ancestor, and were incorporated into the newly-arisen species. Alternatively, closely-related species, because of their genetic similarities, may be predisposed to incorporate particular classes of genetic variants into their gene pools and reject others. In chromosome terms White (1973) has discussed this under the heading of Karyotypic Orthoselection, where lineages show recurrent classes of chromosome changes during evolution.

The chromosome structure of natural populations of the dioecious flowering plant Rumex acetosa has recently been investigated. In this species there is a well-developed and highly-stable sex-chromosome system with $2 n=12+\mathrm{XX}$ in females and $2 n=12+\mathrm{XY} 1 \mathrm{Y} 2$ in males. The $\mathrm{Y}$ chromosomes are highly heterochromatic but maintain size constancy with respect both to the $\mathrm{X}$ and to each other: $\mathrm{Y} 1$ is about 83 per cent of the $\mathrm{X}$ while $\mathrm{Y} 2$ is 74 per cent. At another level, however, the Ys are hypervariable. The centromere of each $Y$ can be located anywhere within the central 40 per cent of the chromosome and there are no preferred sites (Wilby and Parker, 1986; 1987). Centromere position, therefore, behaves as a continuous variable and, on average, every other male in natural populations is distinct on the basis of its Y-composition.

In addition to this Y-chromosome variation, populations are markedly variable in the autosomal complement. Polymorphic supernumerary segments are found on chromosomes 1 and 6 (Wilby and Parker, 1987), and B-chromosomes are common (Wilby, 1987). As well as polymorphic variants, spontaneous structural rearrangements are found in about 2 per cent of seed-grown individuals. Thus Rumex acetosa shows great heterogeneity at the chromosome level and, within populations, identifiably-distinct karyotypes can be displayed by up to 50 per cent of plants (Wilby, 1987).

Rumex acetosa is a member of a subgenus which contains a number of closely-related species 
characterised by this distinctive sex-chromosome system. Indeed the XX/XY1Y2 system has been referred to as "conservative" by one author (Löve, 1969). Although the taxonomy of this group is confused (Tutin, 1964), a number of well-defined, morphologically-distinct entities can be distinguished, occupying a range of habitats from montane to semi-arid, and both perennial and annual. Cytological studies of four species have been carried out to provide informative parallels to the cytological analysis of $R$. acetosa. In particular, the following questions have been addressed:

(a) Is the strict $\mathrm{X}: \mathrm{Y} 1: \mathrm{Y} 2$ size-ratio found in $R$. acetosa maintained in the other species?

(b) Do the Y-chromosomes of all species show hypervariability in centromere position?

(c) Are the autosomal complements constant within the $R$. acetosa group?

(d) Do all species show the autosomal heterogeneity which characterises $R$. acetosa? Chromosome analyses of three perennials- $R$. arifolius, $R$. thyrsiflorus and $R$. thyrsoides-and a single annual $-R$. rothschildianus - are reported in this paper, and are compared to the pattern established in $R$. acetosa.

\section{THE SPECIES}

Rumex arifolius is a plant of alpine meadow and forest, found in the major mountain regions of Europe and Asia. It comes into contact with $R$. acetos $a$ and forms a narrow hybrid zone where the two species meet (Wilby, 1987). Indeed some authors have considered these to be simply ecological replacements (Swietlinska, 1963) but interspecific hybrids undergo at least partial meiotic breakdown.

$R$. thyrsiflorus is a central and eastern European steppe plant favouring dry, free-draining grassland. Hybrids with $R$. acetosa have been reported by a number of authors (Swietlinska, 1963; Zuk, 1963).

$R$. thyrsoides is a species of the arid limestone slopes of countries bordering the western part of the Mediterranean. It has been found to hybridise with $R$. acetosa in southern France (Wilby, 1987).

The single annual species $R$. rothschildianus is a winter annual found in the semi-arid lands bordering the Arabian Desert.

\section{THE COLLECTIONS}

Mature plants of $R$. arifolius were collected from four French populations - two in the Alps and two in the Massif Central-and $R$. thyrsiflorus from a single population by the River Loire in France. In addition seeds of these species and $R$. rothschildianus were obtained from Botanic Garden sources. Seeds of $R$. thyrsoides were collected from plants in natural populations from Aveyron, France.

\section{THE KARYOTYPES}

All five species have the same chromosome number with $2 n=12+\mathrm{XY} 1 \mathrm{Y} 2$ in males and $2 n=12+\mathrm{XX}$ in females. Differences in chromosome organisation have been noted in both the autosomes and the sex-chromosomes and these will be examined separately.

\section{The autosomes}

Three species- $R$. acetosa, $R$. arifolius and $R$. thyrsiflorus-have a common autosomal karytope. In this group of species arm-ratios, nucleolarorganiser regions and chromosome sizes are identical (tables 1 and 2), and in hybrids the parental genomes are indistinguishable. This identity of pattern implies precise homoeology of the complements but studies of F1 hybrid pairing is required to firmly establish this.

All six pairs are acrocentrics with arm-ratios varying from $1: 2 \cdot 3$ (pair 6) to $1: 4 \cdot 6$ (pair 3 ). In length they range from $2.7 \mu \mathrm{m}$ to $4.7 \mu \mathrm{m}$, and in each the nucleolar-organiser region is terminal on the short arm of chromosome 3 (figs 1, 2 and 5). There is a satellite distal to the NOR which is usually small but is variable in size, even approaching the length of the short arm in some individuals.

In Rumex thyrsoides the overall form of the karyotype on the basis of size and arm-ratio is the same as that in the species group outlined above (tables 1 and 2; figs 3 and 5). The nucleolarorganiser region, however, is found terminal on the short-arm of chromosome 1 rather than chromosome 3 . This transposition has little effect on the arm-ratio of either chromosome.

The annual species $R$. rothschildianus has a slightly different karyotpye. Pairs $1-5$ are the same size as in the other species but have slightly reduced short-arms. Chromosome 6, however, is distinctly shorter, only $2.2 \mu \mathrm{m}$, due to a reduced long arm (figs 4 and 5). There is no evidence of an increase in chromosome material elsewhere in the complement. The NOR is located on chromosome 3.

Thus in the autosomes of this subgenus there has been little change from a basic acrocentric plan 
Table 1 Chromosome sizes in microns of five species in the Rumex acetosa group. Asterisks indicate the nucleolar-organiser chromosomes

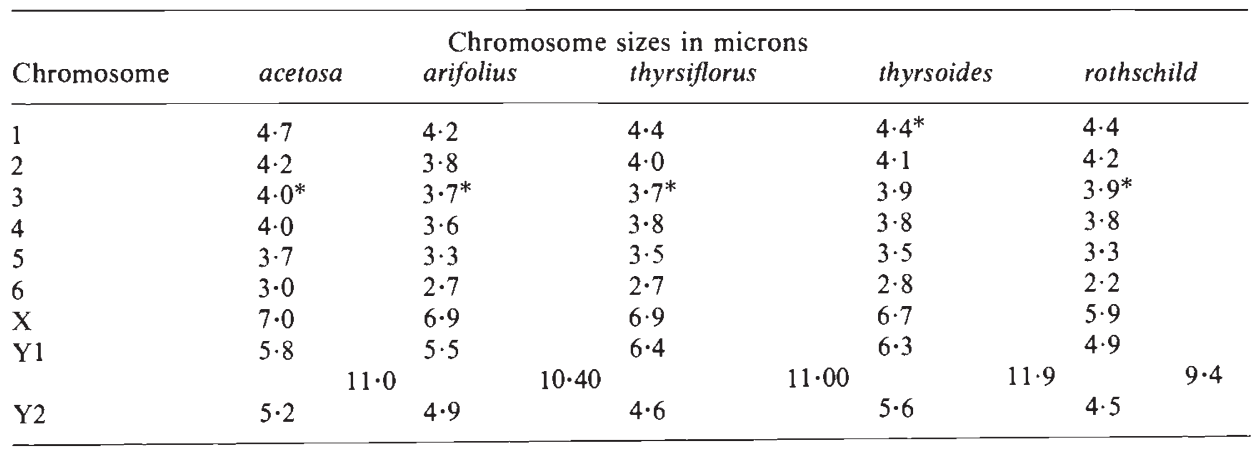

and presumptive homoeologies between species are clear.

\section{The sex-chromosomes}

The X-chromosome in $R$. acetosa, $R$. arifolius and $R$. thyrsiflorus is a euchromatic metacentric of length $7 \mu \mathrm{m}$. The $\mathrm{X}$ of $R$. thyrsoides is the same length but slightly acrocentric (arm ratio $1: 1 \cdot 12$ ). It has a narrow band of heterochromatin near the telomere of the shorter arm. The $\mathrm{X}$ of $R$. rothschildianus is also acrocentric but is only $6 \mu \mathrm{m}$ in length; a heterochromatic band is located near the telomere of the longer arm (figs 1-6).

The Y-chromosomes in all species are heterochromatic with the exception of a minute terminal euchromatic region which corresponds to the pairing segment. The Ys in $R$. acetosa show remarkably little variation in size-Y1 is constantly about 83 per cent the length of the $X$ at colchicinemetaphase and Y2 about 74 per cent (Wilby and Parker, 1986) - and the Ys of $R$. arifolius are indistinguishable. In $R$. thyrsiflorus the total amount of heterochromatin in the Ys is the same as in the previous two species but the distribution is distinctive. Chromosome Y1 is increased to 93 per cent

Table 2 Arm-ratios of five species in the Rumex acetosa group. The Y-chromosomes are omitted due to variable centromere locations

\begin{tabular}{|c|c|c|c|c|c|}
\hline \multirow{2}{*}{$\begin{array}{l}\text { Chromo- } \\
\text { some }\end{array}$} & \multicolumn{4}{|c|}{ Chromosome arm-ratios } & \multirow[b]{2}{*}{ rothschild } \\
\hline & acetosa & arifolius & thyrsiflor & $s$ thyrsoides & \\
\hline 1 & $3 \cdot 74$ & $3 \cdot 64$ & $3 \cdot 87$ & $3 \cdot 35$ & $4 \cdot 10$ \\
\hline 2 & $3 \cdot 66$ & $3 \cdot 88$ & $3 \cdot 68$ & $3 \cdot 89$ & $4 \cdot 58$ \\
\hline 3 & $4 \cdot 63$ & $4 \cdot 58$ & $4 \cdot 62$ & $3 \cdot 86$ & $5 \cdot 98$ \\
\hline 4 & $4 \cdot 31$ & $4 \cdot 25$ & $3 \cdot 86$ & $4 \cdot 09$ & $4 \cdot 51$ \\
\hline 5 & $3 \cdot 18$ & $2 \cdot 58$ & $2 \cdot 73$ & $2 \cdot 99$ & $4 \cdot 03$ \\
\hline 6 & $2 \cdot 28$ & $2 \cdot 33$ & $2 \cdot 24$ & $2 \cdot 17$ & 1.93 \\
\hline $\mathrm{X}$ & $1 \cdot 06$ & 1.05 & 1.05 & $1 \cdot 12$ & $1 \cdot 19$ \\
\hline
\end{tabular}

of the $\mathrm{X}$ while $\mathrm{Y} 2$ is reduced to only 67 per cent. A further difference is that the $\mathrm{Y} 2$ consistently has a constriction near one telomere. This is not associated with the pairing segment (fig. 6).

The amount of Y-material in $R$. thyrsoides is 20 per cent greater than in the above three species. Both Ys are larger-94 per cent and 84 per cent of the $\mathrm{X}$-but interestingly the size relationships are maintained. The final species, $R$. rothschildianus, has $\mathrm{Y} 1$ and $\mathrm{Y} 2$ chromosomes in the same relationship to the $\mathrm{X}$ as $R$ acetosa and $R$. arifolius (83 per cent and 76 per cent). The $\mathrm{X}$ in $R$. rothschildianus, however, is only $6 \mu \mathrm{m}$ in length so the total amount of Y-heterochromatin is reduced by 15 per cent (fig. 6). No pairing segments can be distinguished at mitotic prophase in this species so $\mathrm{Y}$ polarities cannot be established.

\section{Structural variation in Y-chromosomes}

The Y-chromosomes in $R$. acetosa are hypervariable with respect to centromere location (Wilby and Parker, 1986; 1987). The centromeres can be located anywhere within the central 40 per cent of the chromosome without preferred locations. Is this true of other members of the species group? Population samples of suitable size were available for $R$. arifolius and thyrsoides. The few plants of $R$. thyrsiflorus examined give some pointers to the position in this species.

In arifolius, 55 males from four natural populations can be classified into 20 variants with at least one acrocentric $\mathrm{Y}$, giving an average of one recognisable variant in every 2.6 males. The arm-ratios of $Y 1$ and $Y 2$ vary from $0.61+$ to $0.63-$ and $0.60+$ to 0.65 - respectively, in the notation of Wilby and Parker (1986). Centric disposition, therefore, appears to be continuous with no evidence of preferred sites. As with $R$. acetosa, Y1 variants tend to be less extreme than $Y 2$ and there are 

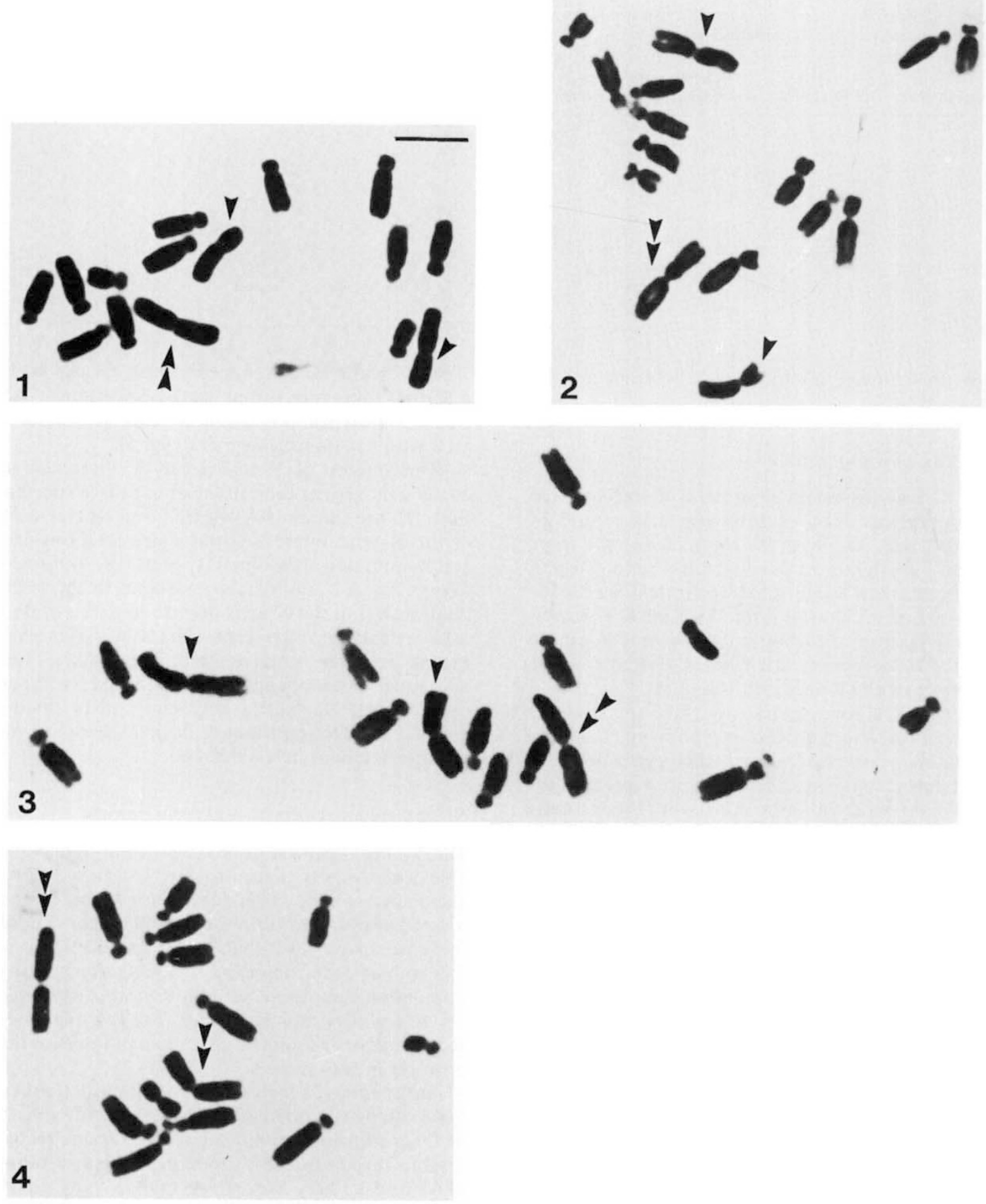

Figures 1-4 Chromosome complements of four species in Rumex subgenus Acetosa. The X-chromosomes are marked by double arrows and the Ys by single arrows. Bar represents $5 \mu \mathrm{m}$.

Figure $1 R$. arifolius. Figure 2 R. thyrsiflorus. Homozygous for supernumerary segments on chromosome 1 and heterozygous for SS5. Figure $3 R$. thyrsoides. Notice satellite on chromosome 1 . Figure $4 R$. rothschildianus. Heterozygous for segment on chromosome 6 . 
RD
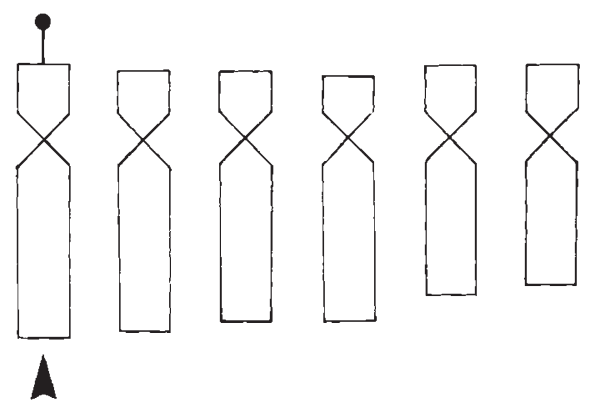

RA
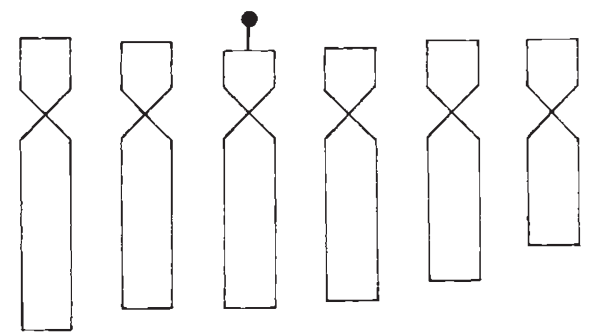

R R
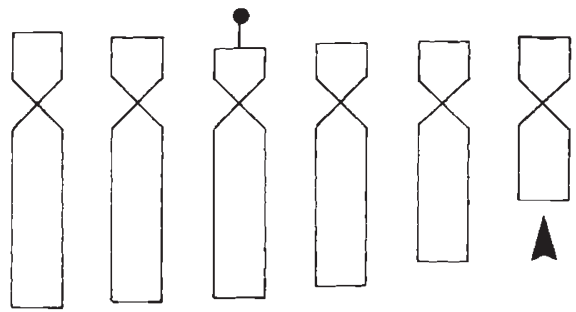

Figure 5 Autosomal karyotypes of five species in the Acetosa group. Three species are indistinguishable-R. acetosa (RA), R. arifolius (RF) and $R$. thyrsiflorus (RS)-while $R$. thyrsoides (RD) and $R$. rothschildianus (RR) each show one change from this pattern.

approximately equal numbers of "+" and "-" variants (Wilby and Parker, 1986).

Other features of Y-variation detected in $R$. acetosa can also be found in this species. Several examples of "telomere shifts", in which pairs of variants in a single population differ in polarity only, have been observed (Wilby and Parker, 1987). In addition, possible evolutionary pathways can be traced: in one population, for example, a Y2 variant with arm-ratio $0 \cdot 60+$ was found in combination with both a metacentric and an acrocentric $Y 2$ of $0.56-$. Finally, a $Y / Y$ interchange in which the Ys are 90 per cent and 61 per cent of the X-length has been found. This frequency of 1 in 55 is remarkably similar to that in $R$. acetosa ( 1 in 64).
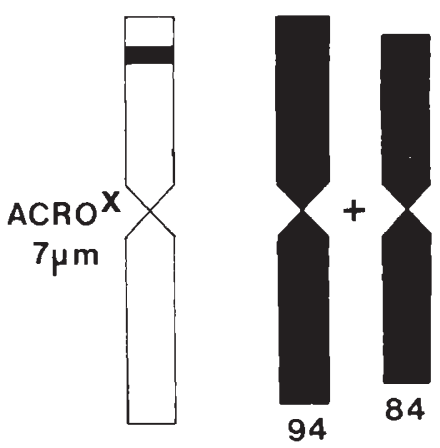

RD
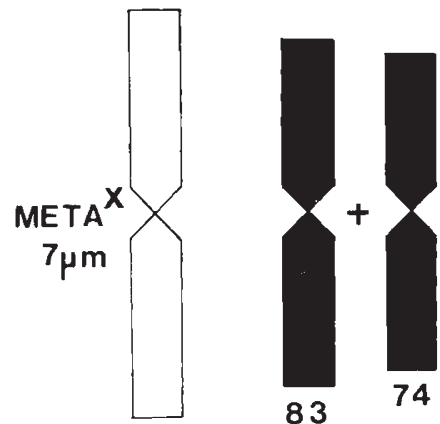

83

RA

RF
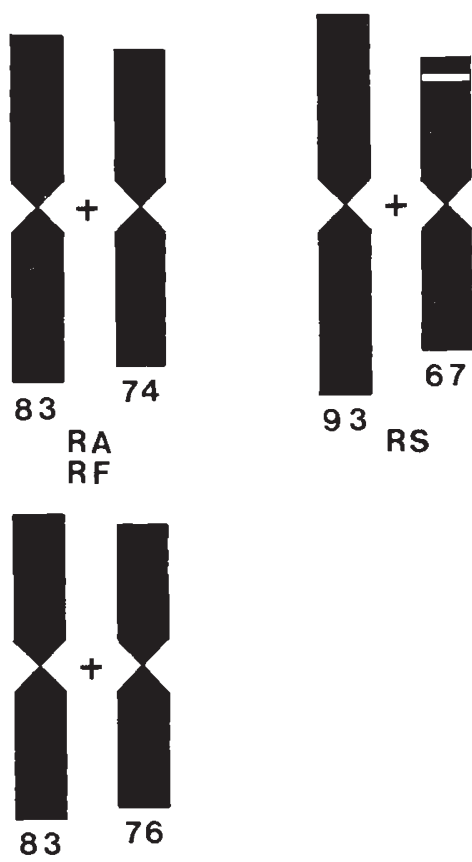

R R

Figure 6 Sex-chromosome karyotypes of the five Acetosagroup species. The $\mathrm{X}$-chromosomes are shown in outline with heterochromatic bands indicated. The $\mathrm{Y} 1$ and $\mathrm{Y} 2$ chromosomes are shown solid. The sizes of the $\mathrm{Ys}$ are given as percentages of the X-chromosome length. The Ys are drawn conventionally as metacentrics.

In $R$. thyrsoides $12 \mathrm{Y}$-variants have been recognised in only 25 males, thus on average every second male is recognisable. The centromere locations in both $\mathrm{Y} 1$ and $\mathrm{Y} 2$ are as variable as in the larger samples of $R$. acetos $a$ and $R$. arifolius and the overall pattern is identical.

Over 1500 males of the Acetosa group have been examined and only one case of a deleted-Y has been found, in the species $R$. thyrsoides. In this plant approximately 50 per cent of the Y1 has been lost from the non-pairing arm. Floral 
development was normal with differentiation of anthers. Meiosis, however, proceeded as far as zygotene but then PMCs died, leading to complete sterility. It is likely then that the deletion occurred in the zygote or embryo.

Only one small collection of $R$. thyrsiflorus has been made and the six males has the same Ykaryotype. However seed samples from Botanic Gardens displayed the standard spectrum of Yvariation. Only one Y-variant was present in the single seed sample of $R$. rothschildianus obtained from a Botanic Garden.

Thus it seems that the pattern of Y-hypervariability described by Wilby and Parker $(1986,1987)$ in $R$. acetosa is characteristic of the whole species group. Presumably, then, the variable centromere locations are as ancient as the evolution of the subgenus and may well be a function of the heterochromatic nature of the Y-chromosomes.

\section{Autosomal polymorphism}

In $R$. acetosa three widely-distributed and frequent polymorphisms are found: supernumerary segment systems on two autosomes, and B-chromosomes (Wilby and Parker, 1986, 1987 and in press).

Supernumerary segments. Heterochromatic supernumerary segments are found on the short arms of chromosomes 1 and 6 in British populations of $R$. acetosa (SS1 and SS6). The segments are 0.5 and $0.4 \mu \mathrm{m}$ in length respectively (Wilby, 1987). SS1 is found as a low frequency polymorphism in the majority of populations while SS6 occurs in about half the British populations at a higher frequency.

Populations of $R$. arifolius are also polymorphic for segments on chromosomes 1 and 6 of approximately the same size as those in $R$. acetosa (fig. 7; table 3). All four populations contained SS1 and two SS6. $R$. arifolius also has a heterochromatic segment on the short arm of chromosome 5 , about $0.6 \mu \mathrm{m}$ in length. The segment was found at a low frequency in two of the four French populations.

The single population of $R$. thyrsiflorus examined was polymorphic for segments on chromosomes 1 and 5 (fig. 7) (table 3). The SS1 is very similar in size to those in $R$. acetosa and $R$. arifolius, but SS5 is only half the length of that in $R$. arifolius. SS5 in $R$. thyrsiflorus is variable, however, since in Botanic Garden seed samples both this SS5 and one similar in size to that in $R$. arifolius have been found.

Both SS1 and SS5 are extremely frequent in $R$. thyrsiflorus. In the French population SS1 had a

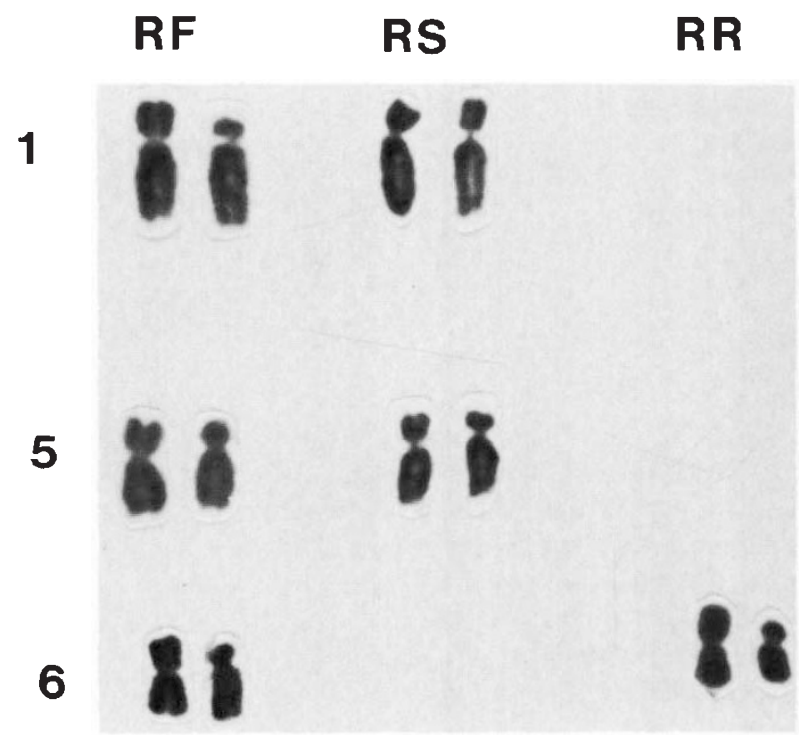

Figure 7 Heterochromatic supernumerary segments in species of Rumex subgenus Acetosa. SS1 in R. thyrsiflorus (RS) is shown homozygous and all others heterozygous.

frequency of $0 \cdot 36$ and SS5 $0 \cdot 68$. All four small seed samples from Botanic Gardens contained both segments in the majority of plants. It would appear that in this species segment-carrying homologues are the standard type.

A single seed sample of $R$. rothschildianus contained heterochromatic segments on the short arm of chromosome 6. Because of the small size of chromosome 6 the segment-bearing chromosomes are metacentric (fig. 4).

In $R$. thyrsoides no supernumerary segments have yet been detected.

$B$-chromosomes. Small euchromatic, usually telocentric, B-chromosomes frequently occur in populations of $R$. acetosa. Bs of similar size have also been found in populations of $R$. thyrsoides and in seed samples of $R$. thyrsiflorus. The Bs in all three species are variable in number between plants, between roots and shoots within plants, and between cells within roots and anthers.

Table 3 Sizes in microns of the supernumerary segments on chromosomes 1,5 and 6 in species of the Rumex acetosa group

\begin{tabular}{|c|c|c|c|}
\hline \multirow[b]{2}{*}{ Species } & \multicolumn{3}{|c|}{ Chromosome } \\
\hline & 1 & 5 & 6 \\
\hline acetosa & 0.5 & - & $0 \cdot 4$ \\
\hline arifolius & 0.7 & 0.6 & 0.5 \\
\hline thyrsiflorus & 0.6 & $0 \cdot 3$ & - \\
\hline rothschildianus & - & - & 0.6 \\
\hline
\end{tabular}




\section{DISCUSSION}

\section{Y-chromosome relationships}

The $\mathrm{Y} 1$ and $\mathrm{Y} 2$ chromosomes of both $R$. acetosa and $R$. arifolius are maintained at 83 per cent and 74 per cent of the X-length despite a Y/Y interchange frequency of 1 in 65 (Wilby and Parker, $1986 ; 1987)$. Evidently this ratio is of selective significance otherwise a continuous spectrum of Y-sizes would be found.

Strict control of the $\mathrm{X}: \mathrm{Y} 1: \mathrm{Y} 2$ ratio is also evident in the other species although the values of those ratios may differ. $R$. thyrsiflorus has the same amount of Y-chromatin although the distribution is distinctive with 93 per cent and 67 per cent of the $\mathrm{X}$ respectively, apparently a fixed $\mathrm{Y} / \mathrm{Y}$ interchange. In $R$. thyrsoides by contrast the Ys are 20 per cent larger although a 10 per cent size difference between $\mathrm{Y} 1$ and $\mathrm{Y} 2$ is maintained. The annual species $R$. rothschildianus has Ys with the same proportions to the $\mathrm{X}$ as those of $R$. acetosa and $R$. arifolius, although the $\mathrm{X}$ itself is smaller.

Thus in this highly-distinctive sex-chromosome system, referred to by Löve (1969) as conservative, only two of the five species cannot be distinguished by Y-morphology alone. Thus although there is a theme there are variations on that theme. What is remarkable is that within a species the Ys remain so constant despite the high frequency of $\mathrm{Y} / \mathrm{Y}$ exchange. Evidently the relative proportions of $\mathrm{Y} 1$ and $Y 2$ are of selective significance, at least within a species, although there is more than one ratio possible within the group.

Although the amount of Y-heterochromatin is not completely fixed there is no variation between individuals within species. Indeed in the only quantitative variant found (in $R$. thyrsoides) total meiotic collapse lead to complete sterility. These heterochromatic chromosomes, although apparently not transcribed, cannot be inert since they are clearly required for the maintenance of pollen fertility. The behaviour of the Y-heterochromatin is therefore different from that of major heterochromatin polymorphisms such as those seen in Scilla sibirica (Vosa, 1973), the human Y-chromosome (Hamerton, 1971) or indeed the supernumerary segment systems of $R$. acetosa (Wilby and Parker, in press), in which all the variants are fertile irrespective of heterochromatin quantity.

\section{Y-chromosome hypervariability}

Centromere position in the Y-chromosomes of $R$. acetosa is a continuous variable within the central
40 per cent of each Y (Wilby and Parker, 1986; 1987 ) and the situation is identical in $R$. arifolius and $R$. thyrsoides. The number of males examined in the other two species is insufficient to give a clear picture of variation in centromere location but the indications are that in $R$. thyrsiflorus at least there is a similar pattern.

It is interesting that the limits to centromere movement seem the same in all species despite the 20 per cent additional chromosome material in $R$. thyrsoides. This suggests that there is a real difference between the central and terminal segments of the Y-chromosomes with respect to mobility and that the size differences are spread uniformly along the whole length of the Ys.

It is likely that the centromere mobility of the Ys in this species group has a common molecular basis, presumably related to the massive blocks of heterochromatin which characterise these chromosomes, and these DNA sequences may be as ancient as the origin of the $\mathrm{XX} / \mathrm{XY} 1 \mathrm{Y} 2$ system itself.

\section{Autosomal relationships}

The autosomal karyotypes of the five species are remarkably constant with all chromosomes highly acrocentric. It is possible to identify tentative homoeologues on morphological grounds although analysis of meiotic pairing in hybrids is required to establish these relationships. The maintenance of overall shape between closelyrelated species is a common observation in both plant and animal groups (Narayan, 1983; White, 1973). The similarities in the Rumex karyotypes are remarkable in view of the fact that a high proportion of novel rearrangements in Rumex acetosa exhibit meiotic drive and centric shifts usually have no effect on fertility in the heterozygous condition (Wilby and Parker, in press).

The karyotpye of $R$. rothschildianus is distinct from the other species in its reduced chromosome 6 . There is no evidence of translocation since the proportions of the remainder of the complement are unaffected. It is interesting that only two deletions have been found in mature plants of this species group, both affecting chromosome 6 of $R$. acetosa (Wilby, 1987). It is possible then that the long arm of chromosome 6 carries few major loci. A number of cases are known where loss of euchromatin is compatible with viability (Finch, 1983).

The only other major autosomal change in the group is the relocation of the nucleolar-organiser region to chromosome 1 in $R$. thyrsoides. This positional change may simply involve the region itself since the arm-ratios remain undisturbed. 


\section{Autosomal polymorphisms}

The close relationships of this species group are emphasised by the parallel polymorphisms for heterochromatic supernumerary segments. Segments on chromosome 1 are found in three species, segments on chromosome 5 in two, and on chromosome 6 in three; only $R$. thyrsoides lacks segments although this may simply reflect limited sampling. The common chromosome location and similarity in size of the segments suggests a common origin pre-dating the speciation events. If this were the case, however, then the segments must either have passed through each evolutionary bottleneck in the heterozygous condition or spread subsequently by hybridisation between species. Spread may have been aided by meiotic drive, detected so far in SS1 of $R$. acetosa (Wilby and Parker, in press). A further possibility is that chromosomes 1,5 and 6 carry sequences on their short arms which are capable of undergoing amplification (John and Miklos, 1979). If this is the case then there must be constraints on the number of copies since the segment sizes are very similar in all species. Segments then are a characteristic and ancient feature of the genetic system of this group of organisms.

A similar pattern to the segments is shown by B-chromosomes. Morphologically- and behaviourally-similar Bs are widespread both within and between species. B-chromosomes with similar properties have been reported, for example, in Japanese populations of $R$. acetosa (Haga, 1961). Again a common and ancient origin for these chromosome elements may be postulated although in the absence of suitable markers homologies both of Bs and of segments can only be presumed.
Acknowledgements ASW was in receipt of an S.E.R.C. postgraduate studentship. JSP wishes to thank the Central Research Fund of the University of London for support in the collection of plant material.

\section{REFERENCES}

DOBZhansky, T. 1970. Genetics of the Evolutionary Process. Columbia University Press, New York.

FINCH, R. A. 1983. Viable long-arm deficiency in diploid barley. Heredity, 50, 191-195.

HAGA, T. 1961. B-chromosomes in Rumex, Scilla and Paris. Proc. Japan Acad., 37, 627-632.

hamerton, J. L. 1971. Human Cytogenetics. Academic Press, New York.

JOHN, B. AND MIKLOS, G. L. G. 1979. Functional aspects of satellite DNA and heterochromatin. Int. Rev. Cytol., 58, $1-114$.

LÖVE, A. (1969). Conservative sex-chromosomes in Acetosa. Chromosomes Today, 2, 166-171.

NARAYAN, R. J. K. 1983. Chromosome changes in the evolution of Lathyrus species. Kew Chromosome Conference II, Brandham, P. and Bennett, M. D. (eds.) Allen and Unwin, London.

SWIETLINSKA, Z. 1963. Cytogenetic relationships among Rumex acetosa, Rumex arifolius and Rumes thyrsiflorus. Acta Soc. Bot. Polon., 32, 215-279.

TUTIN, T. G. 1964. Flora Europaea. Cambridge University Press.

vosA, C. G. 1973. Heterochromatin recognition and analysis of chromosome variation in Scilla sibirica. Chromosoma, 43, 269-278.

White, M. J. D. 1973. Animal Cytology and Evolution. Cambridge University Press.

WILBY, A. S. 1987. Population cytology of Rumex acetosa. Ph.D., University of London.

WILBY, A. S. AND PARKER, J. S. 1986. Continuous variation of hypervariable Y-chromosomes in Rumex acetosa. Heredity, $57,247-254$.

WILBY, A. S. AND PARKER, J. S. 1987. Population structure of hypervariable Y-chromosomes in Rumex acetosa. Heredity, $59,135-143$

ZUK, J. 1963. An investigation on polyploidy and sex-determination within the genus Rumex. Acta Soc. Bot. Polon., 32, 5-72. 